\title{
Effects of Prenatal Stress on Conduction Airway Morphology
}

\author{
Efectos del Estrés Prenatal sobre la Morfología de la vía Aérea de Conducción
}

\author{
Ricardo Henríquez'; Karina Lamoza²; Natalia Soto³ ${ }^{3}$ Fernanda $\operatorname{Lobos}^{3}$ \& Marion Araya ${ }^{3}$
}

HENRÍQUEZ, R.; LAMOZA, K.; SOTO, N.; LOBOS, F. \& ARAYA, M. Efectos del estrés prenatal sobre la morfología de la vía aérea de conducción. Int. J. Morphol., 36(1):319-326, 2018.

RESUMEN: Se sabe que el estrés crónico gestacional altera la respuesta inmune pulmonar, predisponiendo a patologías crónicas pulmonares como el asma, que cursan con alteraciones morfológicas tanto en la vía aérea de conducción como de intercambio. Sin embargo, se desconoce aún si el estrés crónico gestacional genera alteraciones en la morfología pulmonar, específicamente en la vía aérea de conducción, que predisponga a hiperreactividad u otras alteraciones de la vía aérea, en etapas postnatales tempranas. El objetivo de este trabajo consistió en analizar los efectos del estrés prenatal sobre el desarrollo de la vía aérea de conducción pulmonar. Ocho hembras preñadas fueron divididas aleatoriamente en un grupo control y otro grupo sometido a estrés por restricción de movimiento durante la última semana gestacional. Las crías fueron sacrificadas en los días postnatal 0 (P0) y 14 (P14), extrayendoles el pulmón para realizar un análisis histomorfológico de la vía aérea de conducción. En P0 se observó en la vía aérea de conducción un aumento en la musculatura lisa peribronquiolar en machos estresados en comparación al control ( $\mathrm{p}=0,0002)$. No se observaron diferencias significativas en la crías hembra, ni en la etapa de P14. El estrés prenatal produce cambios histomorfológicos en la vía aérea de conducción en las crías de hembras estresadas, en etapas postnatales tempranas.

PALABRAS CLAVE: Estrés prenatal; Pulmón; Morfología.

\section{INTRODUCTION}

Prenatal stress can alter the development of the pregnant organism, through an increase in the release of endogenous glucocorticoids (GCs), by a greater stimulation of the maternal Hypothalamic-Hypophysial-Adrenal (HHA) system (Maestripieri et al., 1991). GCs participate restoring physiological homeostasis of the internal medium and are essential in the maturation of several fetal organs, including brain tissue, skin, gastrointestinal tract and lung tissue, among other is (Audín Parera, 2006). In lung tissue GCs stimulate the production of pulmonary surfactant, cell differentiation, maturation of lung epithelial cells, and can cause thinning of the alveolar walls and septa, facilitating gas exchange after birth. The maternal GCs during gestation do not pass directly to the fetus due to placental 11b-HSD2, which inactivates the GCs with an efficiency close to $80 \%$ (Seckl, 2004). The role of placental 11b-HSD2 will depend on the gestational stage, the sex of the pregnant individual and the expression of the enzyme. Chronic stress conditions in gestational stage produce a poor control of the passage of GCs due to an alteration of the maternal HHA axis. This phenomenon in turn alters the enzymatic barrier of $11 \mathrm{~b}$ HSD2 by decreasing the inactivation of cortisol, facilitating its passage to the fetus (Jensen Peña et al., 2012), exposing it to abnormally high levels of GCs (Pincus-Knackstedt et al., 2006).

It has been observed that the increase of the maternal GCs stimulates the production of placental $\mathrm{CRH}$ and the release of cortisol from the adrenal glands of the fetus, contributing to establish a chronic state of fetal hypercortisolemia (Maestripieri et al.). In addition, GCs produce a sustained increase in plasma concentrations of catecholamines (noradrenaline and adrenaline), which could induce vasoconstriction of the placental arteries, reducing blood flow and therefore the supply of oxygen and nutrients to the fetus, events that Would generate greater activation of the fetal HHA axis (Myers, 1975). Also, the increase in the release of maternal GCs in the third trimester of gestation due to the application of prenatal stress will lead to a downregulation of placental 11b-HSD2 expression (Jensen

\footnotetext{
${ }^{1}$ Escuela de Kinesiología, Facultad de Salud, Universidad Santo Tomas, Chile.

${ }^{2}$ Escuela de Fonoaudiología, Facultad de Salud, Universidad Santo Tomas, Chile.

${ }^{3}$ Facultad de Ciencias, Pontificia Universidad Católica de Valparaíso, Chile.
} 
Peña et al.). Additionally, with the decrease in the activity of this enzyme characteristic of the gestational period (Garbrecht et al., 2007), an excessive passage of GCs to the fetal circulation occurs. Besides, a limitation in the supply of oxygen and nutrients to the fetus resulting from the increase of catecholamines induce in alteration in the fetal HHA axis, effects that would increase the production of GCs and alter the developmental processes of various organs (Pincus-Knackstedt et al.).

Studies in humans have described that prenatal stress predisposes to the offspring of stressed mothers, to suffer cardiovascular alterations, cognitive or emotional problems, among others (Talge et al., 2007). In other studies, it has been observed that under conditions of chronic prenatal stress, alterations in neuronal morphology are generated (Muhammad et al., 2012) and behavior of offspring (de Weerth et al., 2003). This evidence supports Barker's fetal programming theory (Barker, 1998), which describes the existence of critical developmental periods, which are different and specific for each tissue during fetal development (Chrousos, 2009), where a stimulus or a injury at some critical period could trigger long-term or lifetime effects on offspring.

The main function of the pulmonary system is gas exchange and for this to happen the following structures or areas are necessary: i) Gaseous exchange area, ii) Aerial conduction pathways (VCA) and iii) Thoracic cavity or bellows. Pulmonary development, both human and mouse, are similarly staged, despite differences in temporality and duration of lung development stages between the two, but the phases and structural mechanisms are similar (Tschanz et al., 2003). Most of the pulmonary pathologies that affect the pediatric population correspond to obstructive pathologies, where one of the main exponents is asthma and obstructive bronchial syndromes (Yick et al., 2013). In these pathologies an excess of mucus secretion and conduction airway bronchoconstriction (VAC) converge (Yick et al.). There is evidence that tissue and lung function may also be affected by chronic prenatal stress. In this sense, Nogueira et al. (1999) evaluated bronchoalveolar lavage (BAL) in offspring of mothers who were stressed during gestation and later sensitized with ovalbumin (OVA). A higher number of leukocytes, mainly eosinophils, were observed when compared to offspring of non-stressed mothers. Due to this reason the stressed offspring presented a predisposition to allergic respiratory diseases (Nogueira et al.). On the other hand, Pincus-Knackstedt et al. carried out a study in mice in which sonic stress was applied to the mother during the gestational stage and then an OVA sensitization was performed on the offspring. Under these circumstances it was observed that the stressed group had a higher number of eosinophils and macrophages in the BAL, in addition to an increase in the production of bronchial mucus, compared to those not prenatally stressed (Pincus-Knackstedt $e t$ al.). Therefore, based on the data collected, it is known that prenatal stress, in addition to postnatal sensitization, may alter pulmonary immune function, mainly affecting VAC, but it is unknown whether stress could also produce alterations in the morphology of VAC. This situation could predispose the subject, from a structural point of view, to suffer from obstructive pathologies. Therefore, the objective of the present study is to analyze the effects of prenatal stress in the development of pulmonary conduction airways.

\section{MATERIAL AND METHOD}

Animals and laboratory conditions. Eight female mice of the CF-1 strain were used between 3 and 4 months of age. The mice were kept in plexiglass cages, with a reversal of the dark light cycle of 12 hours (20:00 - 8:00), at a temperature of $20+/-2{ }^{\circ} \mathrm{C}$, with water and food ad libitum. They were cleaned twice a week. It should be noted that all animal management and care protocols are in accordance with the Canadian guidelines for care and management of experimental animals (Olfert \& MacWilliam, 1998).

The females were mated, keeping a male with two females in the same cage for one week. During this stage, their estrous cycle was evaluated and the beginning of the gestational stage was defined by vaginal smears. In the last week of gestation, 4 females were randomly selected, which were submitted to a stress restriction protocol of movement, group of stressed females (HE). The remaining 4 were only manipulated for grooming and feeding, being destined to the female control group (HC). In both the mating and gestation phases, the pregnant female was periodically weighed to control the gestational stage and its nutrition.

Chronic prenatal stress protocol and sacrifice. The stress protocol was applied during the third week of gestation, between gestational day 15 (G15) to gestational day 21 (G21), which consisted in restriction of movement by introducing the animal into an opaque PVC tube for 45 minutes, 3 times a day (9:00 a.m., 2:00 p.m. and 6:00 p.m.), for a minimum of 5 consecutive days. At the time of birth, the offspring were sexed and separated according to treatment and sex, randomly distributed offspring to analyze the ages: i) day of delivery (P0 "sacular stage of lung development"); Ii postnatal day 14 (P14 "alveolar stage of lung development"). The offspring of HE will correspond to the stressed group (E) and the offspring of $\mathrm{HC}$ will correspond to the control group (C). 
At stage $\mathrm{P} 0$, the offspring were sacrificed by decapitation, while the offspring selected at stage P14 were sacrificed by intraperitoneal injections of Tiopental (synthetic barbituric). Before being slaughtered, the offspring were weighed.

Histological preparation of lung tissue. After the slaughter of the offspring, in the corresponding stage (P0 and P14), the body weight of each offspring was evaluated, the chest was dissected, lung was extracted, then fixed and stored in bouin solution for 3 days. They were then dehydrated in an ascending alcohol battery (70 \% to $100 \%$ ) for later inclusion in solid paraffin blocks (Paraplast). Parasagittal cuts were performed on each lung (5-7 mm thick). Parasagittal sections of the right lung parahilar area were selected. Each cut had to contain the 3 lobes (apical, medial and basal) and rehydrated in a battery of alcohols of descending concentrations. Hematoxylin-Eosin (H \& E) sections were stained and finally the sample was fixed on a slide for further analysis.

Sample selection and image capture. To measure the VAC parameters, microphotographs of each sample were obtained by means of a digital camera (5.0 CCD Camera) coupled to the Image Pro Software (Image Pro Plus 6.0.0.260) and a photomontage was then taken for measurements. It should be noted that both the histological staining process and the evaluations were performed with masked samples, allowing the evaluator to ignore the group of the sample evaluated. From the VAC, bronchioles were selected that fulfilled the following characteristics: i) bronchioles perpendicular to the cut, ii) closed with the presence of smooth muscle. For the measurement of samples, we used the Image Pro Software (Image Pro Plus 6.0.0.260).

Diameter and smooth muscle area of bronchioles. To measure the diameter of the bronchioles, two perpendicular diameters were drawn, and then the average of these values was drawn. For the smooth muscle area, cells with a tapered morphology corresponding to smooth muscle cells were first identified. Using a polygon of the Image Pro program, the musculature area was measured. These two measurements were performed in the apical, medial and basal areas of the analyzed samples, taking a number of equitable bronchioles per zone and then averaging them. In case of finding significant results, a cell count will be performed to evidence the type of cellular response, evaluating the number of nuclei of cells with characteristic smooth muscle morphology, present in the sample.

Statistic analysis. Descriptive statistics were used with measures of central tendency (average) and measures of dispersion (standard error of the mean) (SEM). In order to analyze the distribution of the groups in question, we first evaluated the normality of the sample with ShapiroWilk test, later applied inferential statistics, $\mathrm{T}$ test for unpaired and parametric data and the Mann Whitney $U$ test for nonparametric non-paired data. The GraphPadPrims 5 program was used for analysis.

\section{RESULTS}

Gestational weight. When analyzing the weight of the pregnant females, no significant differences were observed between the weight of the females of the control group and the group under stress. Both groups present a tendency to increase the weight of females in the first 15 days, with similar weights between $\mathrm{HE}$ group and $\mathrm{HC}$ group. On day $\mathrm{G} 15$, at the beginning of the stress protocol, a decrease in weight was observed in group $\mathrm{HE}$ (HE: $52.6 \mathrm{~g}$ ) compared to HC group (HC: $55.25 \mathrm{~g}$ ), which turns out to be nonsignificant $p=0.2237$. At day $\mathrm{G} 17$ both groups tend to increase their weight without significant differences between them (HE: $61.93 \mathrm{~g}, \mathrm{HC}: 62.09 \mathrm{~g}, \mathrm{p}=0.2$ ). Four strains of stressed pups and four layers of control pups were evaluated. The average number of offspring per litter E was $8.25 \pm$ 0.97 where $57 \%$ were males. In contrast, the average number of litter per litter $\mathrm{C}$ was $11 \pm 0.97$ where $59 \%$ were male.

Weight at sacrifice. When evaluating the weight at the time of slaughter of the male offspring P0, it is observed that the group E presents a significantly lower weight than the group C (E: $1.73 \pm 0.04$ g, C: $1.86 \pm 0.03$ G., $P=0.0114$.) (Fig. 1A). In P14, there were no significant differences in males (E: $11.67 \pm 0.63 \mathrm{~g}, \mathrm{C}: 10.53 \pm 0.41 \mathrm{~g}, \mathrm{p}=0.0646$ ), but a greater tendency to weight gain in group E compared to group C (Fig1B). As for the female offspring P0, it is observed that the group E presents a significantly lower weight than the group $\mathrm{C}(\mathrm{E}: 1.61 \pm 0.03 \mathrm{~g}, \mathrm{C}: 1.75 \pm 0.05 \mathrm{~g}, \mathrm{p}=0.0118)$ (Fig. 1A). In P14, group E presented a significantly higher weight compared to group C (E: $13.1 \mathrm{~g} \pm 1.05 \mathrm{~g}, \mathrm{C}: 9.80 \pm$ $0.34 \mathrm{~g}, \mathrm{p}=0.0057$ ) (Fig. 1B).

Smooth Muscle Area. The peribronchiolar smooth muscle area was measured and the results of group E versus group $\mathrm{C}$, in $\mathrm{P} 0$ and in $\mathrm{P} 14$ were compared and according to the corresponding gender. In P0, group E males $(1.36 \pm 0.28$ $\mathrm{mm}^{2}$ ) had a significantly greater smooth muscle area than in male $\mathrm{C}\left(0.71 \pm 0.08 \mathrm{~mm}^{2}\right), \mathrm{p}=0.0002$ (Fig. 2A) (Fig. 3). When evaluating females, a significant difference was not found between the two groups (E: $0.69 \pm 0.1 \mathrm{~mm}^{2} ; \mathrm{C}: 0.69 \pm$ $0.1 \mathrm{~mm}^{2}$ ) $\mathrm{p}=0.4959$ (Fig. 2A) (Fig. 3). In P14, when evaluating the peribronchiolar smooth muscle area, both, males (E: $4.65 \pm 0.78 \mathrm{~mm}^{2}, \mathrm{C}: 3.79 \pm 0.42 \mathrm{~mm}^{2}, \mathrm{p}=0.3448$ ) 
A

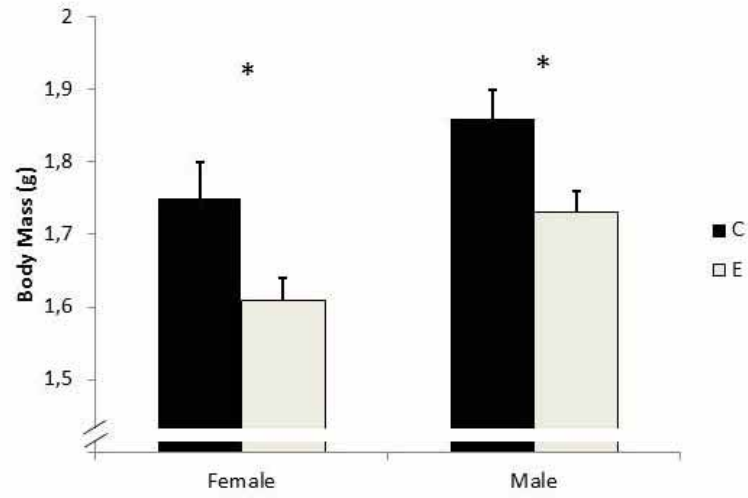

B

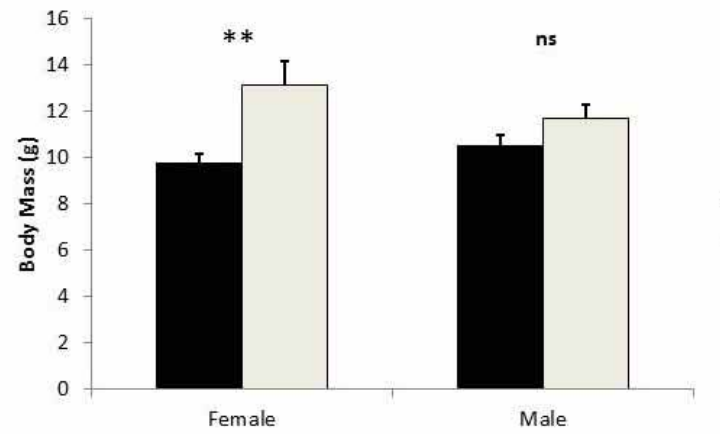

Fig. 1. Body mass of the offspring at the time of sacrifice. A: Postnatal day 1 (p0), Black column: control mother pups (C), Gray column: Stressed mother pups (E). B: Postnatal Day 14 (p14), Black column: control mother pups (C), Gray Column: Stressed mother pups $(\mathrm{E}){ }^{*}=\mathrm{p}<0.05 ; * *=\mathrm{p}<0.01 ; \mathrm{ns}=\mathrm{p}>0.05$ and females (E: $2,38 \pm 0.4 \mathrm{~mm}^{2}, \mathrm{C}: 2.96 \pm 0.41 \mathrm{~mm}^{2}, \mathrm{p}=$ $0.0874)$, no significant differences were found between groups E and C (Fig. 2B) (Fig. 4).

Cell Count. In the groups that have a significant difference of the peribronchiolar smooth muscle area the number of cells of the peribronchiolar smooth muscle area was evaluated and the results of the group E versus the group $\mathrm{C}$ according to the corresponding sex were compared. When evaluating the results, in both, males (E: $41.67 \pm 5.04, \mathrm{C}$ : $34.33 \pm 2.6, \mathrm{p}=0.2)$ and females (E: $30 \pm 2.31 ; \mathrm{C}: 34,33 \pm$ $1.45, \mathrm{p}=0.1$ ), were found no significant differences between groups $\mathrm{E}$ and $\mathrm{C}$ at the age of $\mathrm{P} 0$ (Figs. $2 \mathrm{C}$ and 3 ).

\section{DISCUSSION}

The objective of the present study was to analyze the effects of prenatal stress on the development of pulmonary conduction airway. To achieve this, we worked with an animal model of gestational stress by restriction of movement

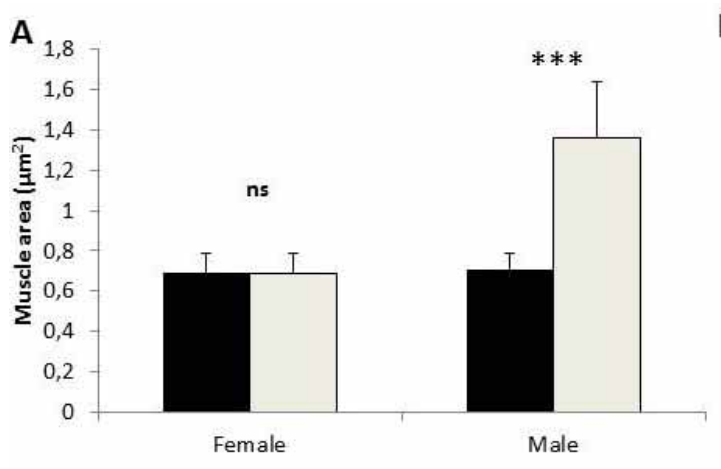

C

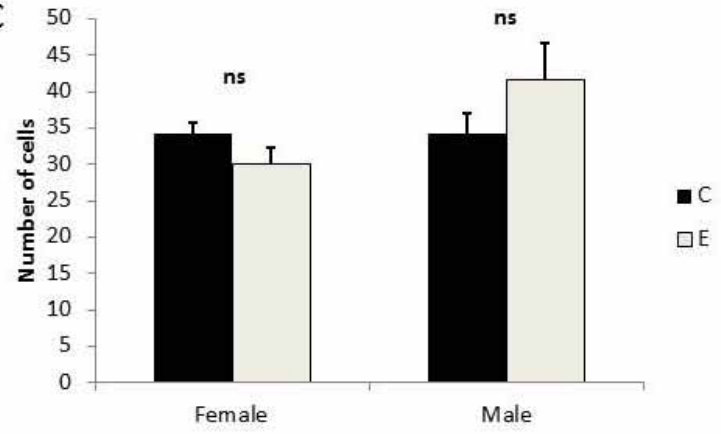

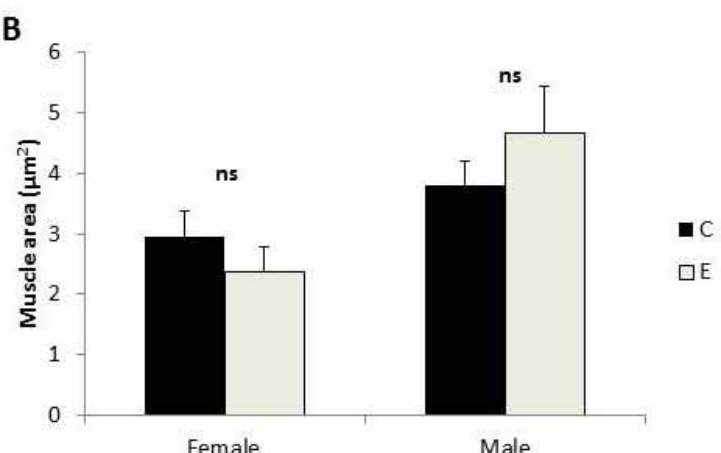

Fig. 2. Histomorphometric analysis of the airway conduction. A: Smooth muscle area, Postnatal day 1 (p0), Black column: control mother pups (C), Gray column: Stressed offspring (E). B: Smooth Muscular Area, Postnatal Day 14 (p14), Black column: control mother pups (C), Gray Column: Stressed mother pups (E). C: Cell count Postnatal day 1 (p0), Black column: control mother pups (C), Gray column: Stressed mother pups (E). $* * *=\mathrm{p}<0.001 ; \mathrm{ns}=\mathrm{p}>0.05$ 


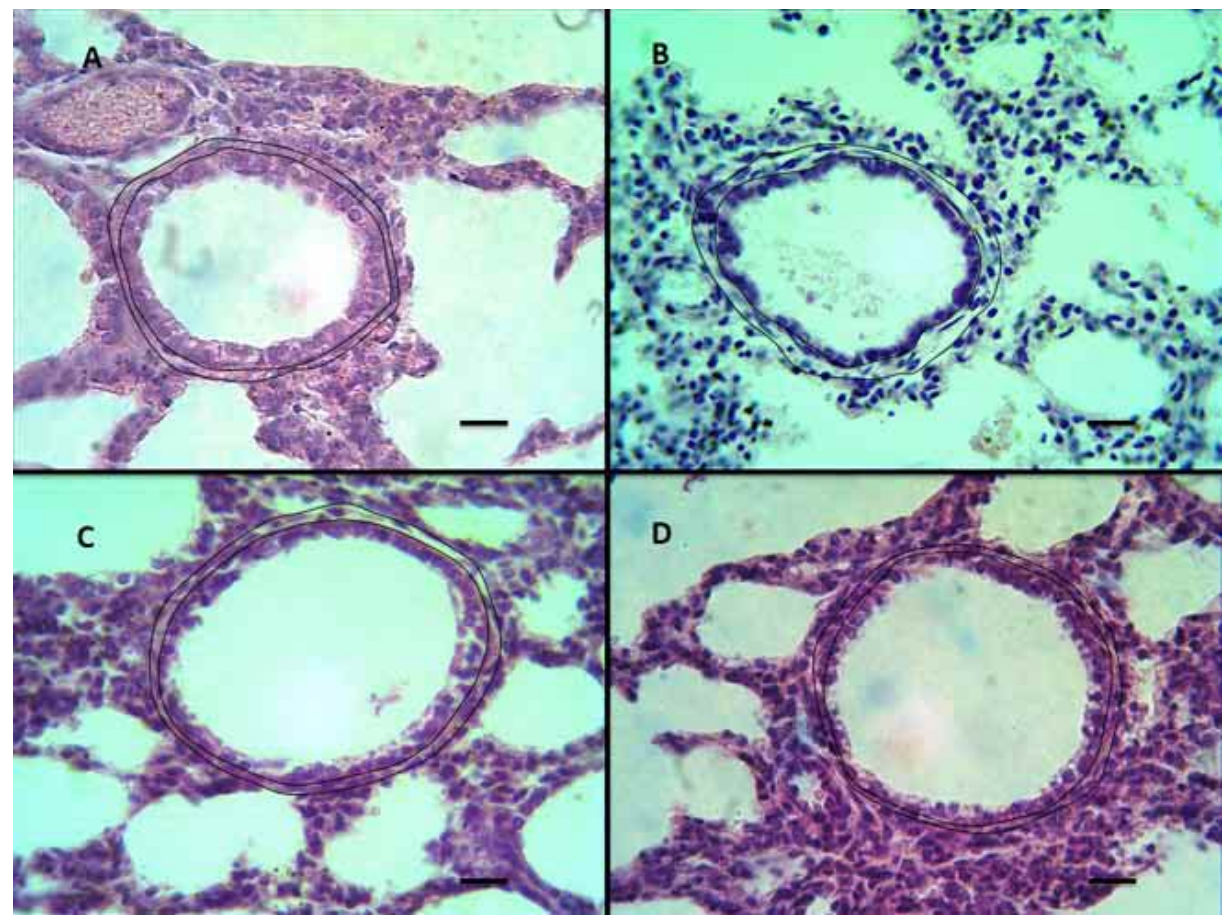

Fig. 3. Representative images age P0, A-B we observed a significant increase in smooth muscular area in male $\mathrm{P} 0$; C-D There are no significant differences in the smooth muscular area of females P0. Hematoxylin eosin stain. A: Male p0 group C; B: Male p0 group E; C: Female p0 group C; D: Female p0 Group E, reference bar $=5 \mu \mathrm{m}$.

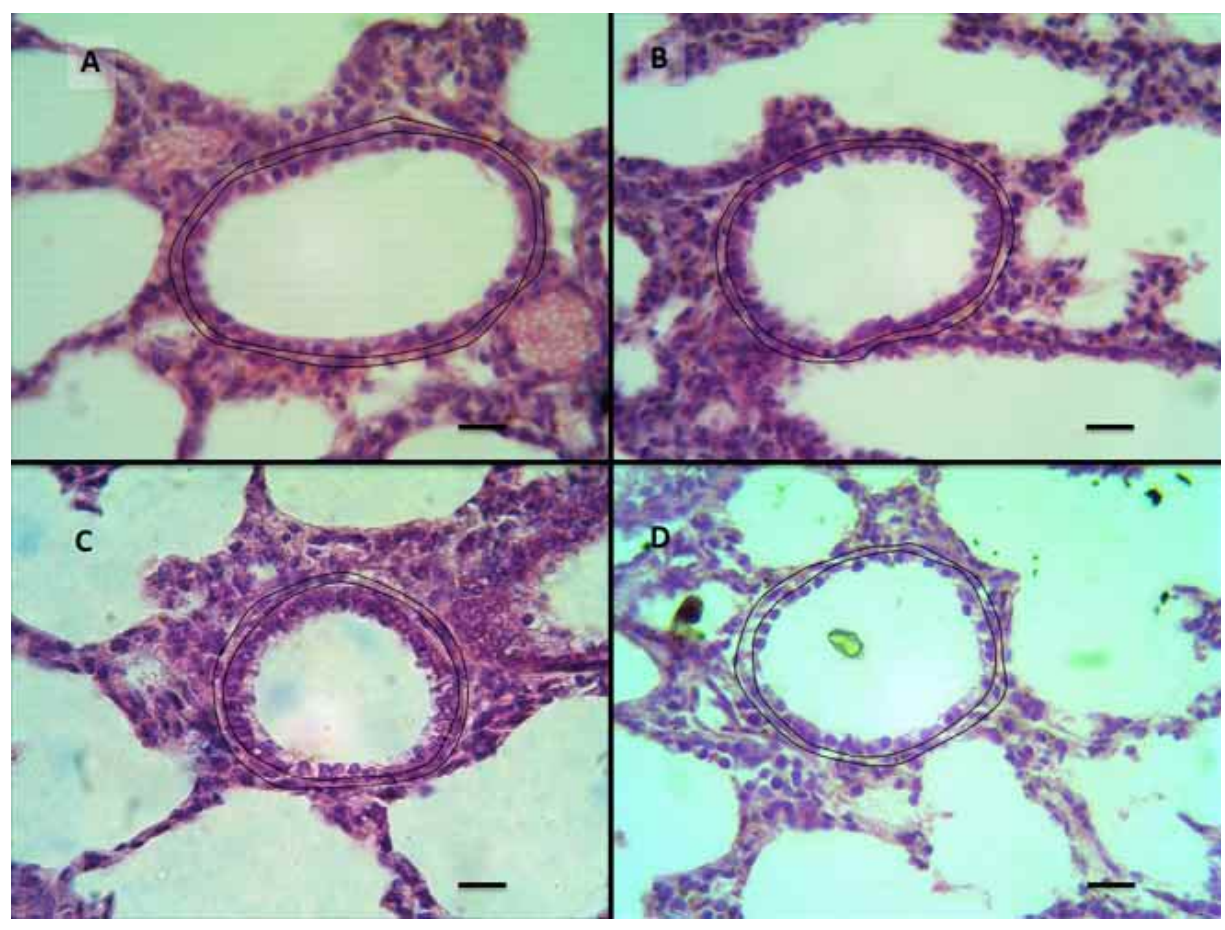

Fig. 4. Representative images age P14. There are no significant differences in the smooth muscular area of females and males P14. Hematoxylin eosin stain. A: Male P14 Control; B: Male P14 stress; C: Female P14 control; D: female P14 stress, reference bar $=5 \mu \mathrm{m}$. 
in the last gestational week. Maestripieri et al. described that this type of stress protocol increases the activity of the HHA axis, promoting the secretion of ACTH and corticosteroid in the female. This increase in CGs due to hyperactivity of the HHA axis could be one of the causes of the alterations evidenced in the results analyzed below.

Gestational weight. When assessing maternal weight, no significant differences were found showing that this stress model does not alter maternal nutrition during the gestational period. There was only a tendency to decrease non-significant weight in $\mathrm{HE}$ with respect to $\mathrm{HC}$ between days G14 and G16, which may be related to the onset of the stress protocol period.

In our study, weight at day P0 was significantly lower in group $\mathrm{E}$ than in group $\mathrm{C}$, in both males and females. Similar results were found in the study by Bolten et al. (2011), who, when assessing the birth weight of prenatally stressed offspring, showed that their weight was lower than the control offspring, in addition they evaluated maternal GC levels and observed which are inversely related to the birth weight of the offspring (Bolten et al.). Based on this evidence, a possible cause of this difference may be the increase in maternal GCs, due to chronic prenatal stress, this increase leads to an increase in maternal catecholamine concentrations, possibly producing vasoconstriction of the placental arteries reducing nutritional intake and oxygen supply to the fetus, resulting in decreased fetal growth (Myers).

On the other hand, the increase in maternal GCs is directly related to fetal hypercortisolemia and in turn with a decrease in the synthesis of various factors such as insulinlike growth factor-1 (IGF-1), transporter protein growth factors similar to insulin type 3 (IGFBP-3) and growth hormone receptor $(\mathrm{GH})$ (Audí Parera), which are key factors in fetal growth. Therefore, the increase of GCs in the female prenatally stressed, could produce a delay in the growth of several tissues in the organism of their offspring, producing a smaller weight at the moment of the birth.

In P14, unlike P0, our study showed that the female offspring of group $\mathrm{E}$ present a significantly higher weight than the offspring of group C. This was also evidenced in the study of Mueller \& Bale (2006), who observed that as a result of a prenatal stress protocol, weight at week 10 increased significantly with respect to their control. This increase in the weight observed in the offspring of prenatally stressed females may be due to the increase in blood glucose produced by the GCs (Mueller \& Bale), which leads to a decrease in the energetic resources of the body tissues. In the present study, there were no significant differences between the two groups. An interesting result is that the pattern of weight gain differs by sex at P14. In the $\mathrm{E}$ female offspring compensate significantly increasing their weight in comparison to the $\mathrm{C}$ offspring, whereas in the $\mathrm{E}$ male offspring, there are no significant differences in their weight compared to the $\mathrm{C}$. These differences between male and female were also evidenced by the study of Dahlgren et al. (2001), in which pregnant dexamethasone (CG group) and saline (control group) were injected in pregnant rats on days 8,10 and 12 of the gestational period and measured their influence on hormonal alterations of adult life in offspring male and female. As a result, at first, weight gain was found in both males and females in the GCs group, being higher in female offspring compared to male offspring. According to the authors, this trend can be explained by an increase in food intake and / or a decrease in physical exercise that would be sex dependent (Dahlgren et al.).

Airway Driving (VAC). It is important to note that this is the first study to show the effects of prenatal stress and morphological alterations in the conduction airway. The results found in our study showed that the area of the peribronchiolar smooth muscle is significantly higher in male E pups evaluated at P0, compared to group C (Fig. $2 \mathrm{~A})$. However, the results were not significant in females of the same age group. Due to this increase in the smooth muscle area of the males P0, we performed a cell count whose results were not significant (Fig. 2C). In the study of Pincus-Knackstedt et al., when stress to the mother during the gestational stage and an OVA sensitization to the offspring were observed, an inflammation of atopic characteristics was observed, specifically in the submucosa area of the airway, and muscle hyperreactivity in the offspring of prenatally stressed mothers. This evidence supports our results regarding the increase of smooth muscle area in group E pups. On the other hand, based on the results of cell counts, the increase of smooth muscle area evidenced in our study could be due to a hypertrophic response of muscle cells rather than to a hyperplastic response. These results could be related to those found in the study by Chen et al. (2011), in which they used mice sensitized with intraperitoneal and aerosol OVA in a chronic manner, evidencing an increase in the smooth muscle area and a greater expression of the transforming growth factor b1 (TGF-b1). This possible increase of TGF-b1, according to Huerta López et al. (2009), could be related to the mechanism of airway hypertrophy conduction. Based on this, the increase in smooth muscle area in our study could be due to a hypertrophic response where increased GCs could stimulate factors such as TGFb1 that promote this type of response (Huerta López et al.). Another possible mechanism involved in the smooth muscle hypertrophy observed in our study is the one proposed by 
Yick et al., who observed that in asthmatic patients with GC treatment, the gene expression of the smooth muscle is altered, causing an increase in the size of the peribronchial smooth muscle fiber. On the other hand Kanse et al. (1991) argues that GCs not only directly affect the smooth muscle, but also indirectly, since it would induce the increase of the endothelial expression of endothelin 1, cytokine that has been correlated with contraction of the smooth muscle and as a powerful mitogenic agent, predisposing to an increase in muscle fiber size.

The increased area in the peribronchiolar smooth muscle, found in E males, is a factor that predisposes to a smooth muscle hyperreactivity of the conduction airway, which, together with factors of genetic and immunological predisposition, could develop future diseases chronic respiratory obstruction (Huerta et al.). This possibility has already been observed in humans, where several studies suggest that there is a direct relationship between gestational stress (van de Loo et al., 2015) and prenatal exposure to GCs with the development of pathologies such as asthma. Regarding the sexual differences, in our study a smooth peribronchiolar smooth muscle area in $\mathrm{P} 0$ is evidenced significantly greater in males, but in females there is no significant difference. With respect to this, in the study by Condon et al. (1997) they observed in placental tissue a small decrease in the free and conjugated rate of active GCs compared to the rate of inactive GCs in females as opposed to males, suggesting A greater activation of the 11b-HSD2 enzyme in the female sex. Therefore it could be said that offspring of prenatally stressed females have less influence on maternal GCs than did male offspring (Condon et al.). On the other hand, Stark et al. (2009) when women administered prenatal betamethasone (from 24 to 36 weeks of gestation) evaluated in the postnatal stage the activity rate of the placental 11b-HSD2 enzyme plus the concentration of GCs in the umbilical artery, resulting in that in the treated women With betamethasone, the concentration of postnatal GCs and the rate of placental 11b-HSD2 activity was higher in female offspring compared to male offspring. This suggests that in our study, female offspring may have had a greater ability to selfregulate the activity of the 11b-HSD2 enzyme to modulate the effects of prenatal stress.

\section{CONCLUSION}

Prenatal stress alters the conduction airway morphology in a sex dependent manner, producing changes that could favor bronchial hyperreactivity and the appearance of obstructive pathologies in later stages.
HENRÍQUEZ, R.; LAMOZA, K.; SOTO, N.; LOBOS, F. \& ARAYA, M. Effects of prenatal stress on conduction airway morphology. Int. J. Morphol., 36(1):319-326, 2018.

SUMMARY: It is known that chronic gestational stress alters the pulmonary immune response predisposing to chronic pulmonary pathologies such as asthma, which occur with morphological alterations in both conduction and exchange airways. However, it is still unknown whether chronic gestational stress generates alterations in pulmonary morphology, specifically in the airway conduction, which predisposes to hyperreactivity or other alterations of the airway, in early postnatal stages. The aim of this work was to analyze the effects of prenatal stress on the development of pulmonary conduction airway. Eight pregnant females were randomly assigned to one control group and one group submitted to restriction of movement during the last gestational week. The offspring were sacrificed on postnatal days 0 (P0) and 14 (P14), extracting the lung to conduct a histomorphological analysis of the conduction airway. In P0 an increase in the peribronchiolar smooth muscle in stressed males was observed in the conduction airway in comparison to the control $(p=0.0002)$; no significant differences were observed in the female or in the P14 stage. Prenatal stress produces histomorphologic changes in the conduction airway in the offspring at early postnatal stages.

\section{KEY WORDS: Prenatal stress; Lung; Morphology.}

\section{REFERENCES}

Audí Parera, L. Crecimiento fetal y glucorticoides. Med. Clin., 127(10):3768, 2006.

Barker, D. J. In utero programming of chronic disease. Clin. Sci. (Lond.), 95(2):115-28, 1998.

Bolten, M. I; Wurmser, H.; Buske-Kirschbaum, A.; Papousek M.; Pirke K. \& Hellhammer, D. Cortisol levels in pregnancy as a psychobiological predictor for birth weight. Arch. Womens Ment. Health, 14(1):33-41, 2011.

Chen, M.; Lv, Z. \& Jiang, S. The effects of triptolide on airway remodelling and transforming growth factor-b?/Smad signalling pathway in ovalbumin-sensitized mice. Immunology, 132(3):376-84, 2011.

Chrousos, G. P. Stress and disorders of the stress system. Nat. Rev. Endocrinol., 5(7):374-81, 2009.

Condon, J.; Ricketts, M. L.; Whorwood, C. B. \& Stewart, P. M. Ontogeny and sexual dimorphic expression of mouse type 211 beta-hydroxysteroid dehydrogenase. Mol. Cell. Endocrinol., 127(2):121-8, 1997.

Dahlgren, J.; Nilsson, C.; Jennische, E.; Ho, H. P.; Eriksson, E.; Niklasson, A.; Björntorp, P.; Albertsson Wikland, K. \& Holmäng, A. Prenatal cytokine exposure results in obesity and gender-specific programming. Am. J. Physiol. Endocrinol. Metab., 281(2):326-34, 2001.

de Weerth, C.; van Hees, Y. \& Buitelaar, J. K. Prenatal maternal cortisol levels and infant behavior during the first 5 months. Early Hum. Dev., 74(2):139-51, 2003.

Garbrecht, M. R.; Klein, J. M.; McCarthy, T. A.; Schmidt, T. J.; Krozowski, Z. S. \& Snyder, J. M. 11-Beta hydroxysteroid dehydrogenase type 2 in human adult and fetal lung and its regulation by sex steroids. Pediatr. Res., 62(1):26-31, 2007.

Huerta López, J.; Jiménez Gutiérrez, C.; del Olmo Téllez, H. \& Maza López, M. Remodelación de la vía aérea en asma. revisión. Alerg. Asma Inmunol. Pediatr. 18(2):60-78, 2009. 
Jensen Peña, C.; Monk, C. \& Champagne, F. A. Epigenetic effects of prenatal stress on 11b-hydroxysteroid dehydrogenase- 2 in the placenta and fetal brain. PloS One, 7(6):e39791, 2012.

Kanse, S. M.; Takahashi, K.; Warren, J. B.; Ghatei, M.; \& Bloom, S. R. Glucocorticoids induce endothelin release from vascular smooth muscle cells but not endothelial cells. Eur. J. Pharmacol., 199(1):99-101, 1991.

Maestripieri, D.; Badiani, A. \& Puglisi-Allegra, S. Prepartal chronic stress increases anxiety and decreases aggression in lactating female mice. Behav. Neurosci., 105(5):663-8, 1991.

Mueller, B. R. \& Bale, T. L. Impact of prenatal stress on long term body weight is dependent on timing and maternal sensitivity. Physiol. Behav., 88(4-5):605-14, 2006

Muhammad, A.; Carroll, C. \& Kolb, B. Stress during development alters dendritic morphology in the nucleus accumbens and prefrontal cortex. Neuroscience, 216:103-9, 2012.

Myers, R. E. Maternal psychological stress and fetal asphyxia: a study in the monkey. Am. J. Obstet. Gynecol., 122(1):47-59, 1975.

Nogueira, P. J.; Ferreira, H. H.; Antunes, E. \& Teixeira, N. A. Chronic mild prenatal stress exacerbates the allergen-induced airway inflammation in rats. Mediators Inflamm., 8(2):119-22, 1999.

Olfert, E. D. \& MacWilliam, A. A. Manual sobre el Cuidado y Uso de los Animales de Experimentación. Toronto, Consejo Canadiense de Protección de Animales, 1998.

Pincus-Knackstedt, M. K.; Joachim, R. A.; Blois, S. M.; Douglas, A. J.; Orsal, A. S.; Klapp, B. F.; Wahn, U.; Hamelmann, E. \& Arck, P. C. Prenatal stress enhances susceptibility of murine adult offspring toward airway inflammation. J. Immunol., 117(12):8484-92, 2006.

Seckl, J. R. Prenatal glucocorticoids and long-term programming. Eur. J. Endocrinol., 151 Suppl. 3:U49-62, 2004.

Stark, M. J.; Wright, I. M. \& Clifton, V. L. Sex-specific alterations in placental 11 betahydroxysteroid dehydrogenase 2 activity and early postnatal clinical course following antenatal betamethasone. Am. J. Physiol. Regul. Integr. Comp. Physiol., 297:R510-4, 2009.

Talge, N. M.; Neal, C.; Glover, V. \& Early Stress, Translational Research and Prevention Science Network: Fetal and Neonatal Experience on Child and Adolescent Mental Health. Antenatal maternal stress and long-term effects on child neurodevelopment: how and why? J. Child Psychol. Psychiatry, 48(3-4):245-61, 2007.

Tschanz, S. A.; Makanya, A. N.; Haenni, B. \& Burri, P. H. Effects of neonatal high-dose short-term glucocorticoid treatment on the lung: a morphologic and morphometric study in the rat. Pediatr. Res., 53(1):7280, 2003.

van de Loo, K. F.; van Gelder, M. M.; Roukema, J.; Roeleveld, N.; Merkus, P. J. \& Verhaak, C. M. Prenatal maternal psychological stress and childhood asthma and wheezing: a meta-analysis. Eur. Respir. J., 47(1):133-46, 2015

Yick, C. Y.; Zwinderman, A. H.; Kunst, P. W.; Grünberg, K.; Mauad, T.; Fluiter, K.; Bel, E. H.; Lutter, R.; Baas, F. \& Sterk, P. J. Glucocorticoidinduced changes in gene expression of airway smooth muscle in patients with asthma. Am. J. Respir. Crit. Care Med., 187(10):1076-84, 2013.

\author{
Dirección para correspondencia: \\ Ricardo Henríquez Flores \\ Avenida. 1 Norte \#3041, piso 5 \\ Escuela de Kinesiología \\ Viña del Mar \\ CHILE
}

Email: r.henriquez.f@gmail.com

Recibido: 30-09-2017

Aceptado:03-01-2018 